Something in the air

\author{
S.A. Penkett
}

Chemistry of the Natural Atmosphere. By Peter Warneck. Academic: 1988. Pp.757. $\$ 85, £ 63$.

Although scientific observations of the composition of the atmosphere were made in the 1700 s and earlier, the real roots of atmospheric chemistry lie in the studies of ozone and the acidity of rainwater carried out in the last century. The subject has matured only slowly but today atmospheric chemistry stands as a recognizably distinct discipline, not the least of the indicators being the increasing amount of attention publishers have paid to it.

Two books published in the early $1960 \mathrm{~s}$ set the pattern for later authors. One, Photochemistry of Air Pollution by Philip Leighton, dealt with the subject from the point of view of a laboratory photochemist. The other, Christian Junge's Air Chemistry and Radioactivity, concentrated on presenting and interpreting observations of the meteorological and chemical behaviour of trace gases and aerosols in a global atmosphere. Peter Warneck's book fits into this second mould - not surprisingly perhaps, because Warneck was for many years a co-worker of Junge at the Max Planck Institute for Chemistry in Mainz.

Much has changed since the first appearance of Leighton's and Junge's books. For instance the original hypothesis proposed to account for the chemistry of stratospheric ozone has been displaced by theories emphasizing the role of minor trace gases, including nitrogen oxides and halogen compounds, in catalytic destruction cycles. Also in the troposphere, a universal oxidation mechanism has been discovered whereby most trace gases emitted from the Earth's surface are destroyed by reaction with free radicals and peroxides before they can reach the stratosphere. Both in the stratosphere and the troposphere, therefore, atmospheric chemists are mainly concerned with the role of trace gases, with their emissions, their distribution and their chemical interactions, which in many cases are initiated by the absorption of sunlight.

Warneck's text deals predominantly with such phenomena as they occur in the troposphere, and is more thorough than many others in treating both gaseous and particulate species in similar depth. It also covers the atmospheric aqueous phase extensively, both from a physical and a chemical point of view. There is much fascinating detail on observational data which not only makes the book unusually interesting to browse in, but, with its phases on the homogeneous gas-phase chemistry, a topic that is becoming increasingly relevant both for the case of cloud droplets in the troposphere and for ice particles in the stratosphere which increase the efficiency of ozone removal over Antarctica. The omission is partly, but not entirely, explained by the fact that the literature survey - which is otherwise reasonably thorough - largely ceased in 1985.

This is a book which has several unique features, and which will be of interest to most atmospheric scientists. In particular, the material is ideal for teaching postgraduate students about the chemistry of the natural atmosphere and its response to increasing emissions of pollutants.

S.A. Penkett is in the School of Environmental Sciences, University of East Anglia, Norwich NR4 7TJ, UK

\section{Solid solutions}

\section{Paul W. Williams}

Geomorphology and Hydrology of Karst Terrains. By William B. White. Oxford University Press:1988. Pp.464. £35, \$45.

William White adopts the Soviet view that landforms produced by solution processes constitute karst. By that definition about 20 per cent of the Earth's land surface can be considered karstic, and this book deals with the landforms and hydrology of such terrains.

Until the 1960 s karst research was largely the preserve of Europeans. North Americans made comparatively few contributions to the subject, despite the fact that about 20 per cent of the coterminous United States is composed of carbonate rocks, with additional huge areas of even more soluble evaporites. Since then the situation has changed markedly, and scientists such as William White have risen to international prominence.

White and his associates are particularly well known for their work on carbonate geochemistry and groundwater hydrology, and especially for linking solution kinetics of limestones to cave and aquifer development. From a base in Pennsylvania State University, the extensive karsts of the nearby Appalachians and Kentucky have provided numerous field sites to test and develop hypotheses. This volume largely records that experience, which has accumulated over more than 25 years.

The form of the book is closer to a series of essays than to an account integrated by a pervading theme or conceptual approach. Consequently, it will be of greater value for professionals in related fields than for undergraduates. This is in keeping with one of the author's primary objectives, that of writing a book suitable for water-supply specialists, urban planners and environmental engineers. The suited for a North American readership.

White identifies three essential features of the karstification process: the hydrogeological setting, the chemical driving force and the physical driving force. In developing these points, he provides notable accounts of carbonate dissolution, the mechanics of groundwater flow and the geochemistry of karst waters. His command of these fields on occasion results in authoritative pronouncements on the linkages between laboratory theory and field evidence. This is a rare talent and is well exemplified here in the discussion of the processes of karst conduit and aquifer development. White is less successful in forging a link between chemical-hydrological theory and surface landform development. So the geomorphological content is comparatively conventional, except in the section on karst and karst-like features in slightly soluble rocks.

The concluding chapters concentrate on the application of our knowledge of karst to a range of practical problems. Water resource contamination, foundation engineering, sinkhole collapse and flooding are all the subjects of broad and useful surveys that will be especially helpful to environmental managers.

Paul W. Williams is in the Department of Geography. University of Auckland, Private Bag. Auckland. New Żealand.

\section{New in paperback}

- Thermoluminescence of Solids by S.W.S McKeever. Publisher is Cambridge University Press, price is $£ 17.50, \$ 34.50$. For review see Nature 317. 122 (1985).

- Dinosaurs Past and Present, Vols I and II, lisher is University of Washington Press, price is $\$ 22.95$ per volume. Available in Britain from British Museum (Natural History), $£ 19.95$ each. choice of examples also makes it best edited by S.J. Czerkas and E.C. Olson. Pub- 